\title{
MODEL SOSIAL BISNIS PAGUYUBAN PENGEPUL SAMPAH MANDIRI TANGERANG SELATAN DENGAN PENDEKATAN ERGONOMI PARTISIPASI
}

\author{
Helena Juliana Kristina ${ }^{1, a}$, Wilson Kosasih ${ }^{1, b}$, Lithrone Laricha Salomon ${ }^{1, c}$ \\ ${ }^{1}$ Program Studi Teknik Industri, Fakultas Teknik Universitas Tarumanagara \\ e-mail: julianak@ft.untar.ac.id ${ }^{\mathrm{a}}$,wilsonk@ft.untar.ac.id ${ }^{\mathrm{b}}$, lithrones@ ft.untar.ac.id ${ }^{\mathrm{c}}$
}

\begin{abstract}
ABSTRAK
Pengelolaan sampah berbasis komunal dengan orientasi ekonomi diharapkan dapat mengurai masalah sampah di Indonesia. Namun, kerja sama dan kolaborasi kegiatan antar lembaga keduanya baik sosial dan ekonomi perlu digalakkan. Sementara itu, komunitas pengelolaan sampah mutlak harus ada demi perubahan paradigma dan keberlanjutan di masyarakat, baik dalam gerakan sosial maupun perekayasaan sosial. Penelitian ini bertujuan untuk mengembangkan model sosial bisnis paguyuban pengepul sampah mandiri di kota Tangerang Selatan. Penelitian ini adalah eksploratory study yang telah mengumpulkan data menggunakan pendekatan ergonomi partisipasi dengan wawancara terstruktur (in-depth interview) dan peta empati B2B. Peta empati tersebut menganalisis demografi para pengepul sampah mandiri, dan mengembangkan pemahaman yang lebih baik tentang lingkungan, perilaku, kepedulian dan aspirasi mereka. Hasilnya, studi ini mengusulkan model sosial bisnis sebagai fondasi pendirian paguyuban pengepul sampah mandiri.
\end{abstract}

Kata kunci: Ergonomi Partisipasi, Pengelolaan sampah, Peta Empati B2B, Model Sosial Bisnis, Paguyuban Pengepul Sampah.

\begin{abstract}
Communal-based waste management with an economic orientation is expected to solve the waste problem in Indonesia. However, cooperation and collaborative activities between both social and economic institutions need to be encouraged. Meanwhile, a waste management community is absolutely necessary for a paradigm shift and sustainability in society, both in social movements and social engineering. This study aims to develop a social business model for an independent waste collector association in the city of South Tangerang. This research is an exploratory study that has collected data using a participatory ergonomics approach with in-depth interviews and B2B empathy maps. The empathy map analyzes the demographics of independent waste collectors, and develops a better understanding of their environment, behavior, concerns and aspirations. As a result, this study proposes a social-business model as the foundation for the establishment of an independent waste collector association.
\end{abstract}

Keywords: Participatory Ergonomics, Waste Management, B2B Empathy Map, Social Business Model, Waste Collector Association.

\section{PENDAHULUAN}

Dalam pengelolaan sampah yang baik, diperlukan kerja sama antar pemangku kepentingan yang berhubungan dengan bisnis ekonomi sampah. Para pemangku kepentingan meliputi pemerintah, pemda, pengepul sampah swasta, perkumpulan industri yang peduli pada sampah kemasannya, pabrik daur ulang, bank sampah, sekolah hijau, pemulung, dan komunitas masyarakat mandiri yang peduli pada permasalahan sampah di wilayahnya. Pengelolaan sampah berbasis komunal dengan orientasi ekonomi diharapkan dapat mengurai masalah sampah di Indonesia. Hal ini sejalan dengan UU 18 Tahun 2008 tentang Pengelolaan Sampah serta regulasi lainnya [1]. Namun, kerja sama dan kolaborasi kegiatan antar lembaga keduanya baik sosial dan ekonomi perlu digalakkan. Sementara itu, komunitas pengelolaan sampah mutlak harus ada demi perubahan paradigma dan keberlanjutan di masyarakat, baik dalam gerakan sosial maupun perekayasaan sosial [2]. 


\section{Helena Juliana Kristina, Wilson Kosasih, Lithrone Laricha Salomon}

Keterlibatan masyarakat dan pemangku kepentingan adalah sangat penting agar bisnis pengelolaan sampah yang mendukung sirkular ekonomi tetap dapat berfungsi dan tercipta lingkungan yang bersih sebagai dampaknya. Pengelolaan sampah dengan sistem ekonomi melingkar atau circular economy, memerlukan bahan baku/sampah yang bersih sejak dari sumbernya, karena material ini akan dipergunakan oleh industri lainnya. Semakin mahalnya sumber daya alam, sedangkan ekonomi harus tetap tumbuh, maka segala sesuatu nilai sumber daya ekonomi, termasuk yang sudah menjadi sampah, harus dimanfaatkan, agar ketika masa pakainya habis dapat di daur ulang dan di manfaatkan kembali berkali-kali, oleh industri lain [3]. Program bank sampah yang sudah ada di Indonesia dapat digunakan sebagai salah satu pintu masuk terwujudnya reverse logistic rantai pasok manufaktur berkelanjutan [4]. Oleh karena itu, sistem kumpul, angkut, pilah, buang (linear economy) yang orientasi pengelolaan sampahnya di tempat pembuangan akhir sudah harus diubah, mengingat daya tampung TPA yang makin menipis. Hasil riset KLHK bekerja sama dengan Danone, AQUA dan Sustainable Waste Indonesia, menunjukkan bahwa tingkat daur ulang plastik hanya 7\%. Masih banyak sampah plastik yang sebenarnya bisa di daur ulang, namun masih di timbun di Tempat Pemrosesan Akhir Sampah (TPA), sekitar 60\%, dan bahkan bocor ke lingkungan sekitar 24\% [3].

Di sisi lain, untuk pemangku kepentingan industri daur ulang, maupun lapak/pengepul sampah dalam kegiatan jual-beli sampah botol plastik, toleransi mutu pasokan menjadi hal penting. Toleransi yang diberikan oleh pabrik adalah sebesar 5\% dari kuantitas pasokan, dikarenakan pabrik tidak mau lagi men-sortir barang yang sudah dikirim oleh lapak karena hanya akan menambah waktu dan biaya operasi [5]. Demikian halnya kondisi kualitas pengiriman mempengaruhi perolehan harga beli dari pabrik daur ulang kemasan tetra pak/UBC. Dikarenakan pengepul percontohan kemasan tetra pak dari sumber bank sampah/komunitas masyarakat lainnya, mengirim dalam keadaan pres manual dan packaging karung serta mengandung sedotan, maka dari checker, pengepul mendapat potongan $25 \%$ dari harga belinya, dan hal ini merugikan pengepul [6].

Pengelolaan partisipatoris akan menimbulkan kepercayaan sosial, dan dalam hal ini perlu terus dibangun hubungan kerja sama dan saling menghargai antar semua mitra [7]. Proyek percontohan kerja sama pengelolan sampah mandiri, yang melibatkan bank sampah, pengepul sampah swasta dan relawan/komunitas peduli lingkungan hidup, dengan menggunakan penerapan konsep ergonomi partisipasi telah dilakukan di Tangerang Selatan wilayah Pamulang. Proyek ini cukup berhasil, dikarenakan tujuan tercapai, ada partisipasi dari semua mitra, bahkan beberapa mitra memberikan partisipasinya melebihi target rencana awal. Para partisipan memiliki pengendalian terhadap dirinya untuk leluasa bertindak atau sejauh mana dirinya mampu mengatasi keterbatasan dalam bertindak dan mau bersikap terbuka dalam partisipasi. Partisipan mempunyai keyakinan diri mengenai mudah atau sulitnya mewujudkan hal yang ingin dilakukannya dalam proyek, dan ini membentuk persepsi pengendalian perilaku, dimana hal ini selain ditentukan oleh kompetensi partisipan yang bersangkutan, juga oleh ketersediaan sumber daya berupa peralatan, materi dan kesempatan yang mendukung perilaku partisipasi tersebut.

Ergonomi partisipasi merupakan terlibatnya orang secara mental dan emosional di dalam satu komunitas yang merangsang mereka untuk berkontribusi kepada tujuan kelompok dan berbagi tanggung jawab untuk apa yang dihasilkannya [8]. Ergonomi partisipasi, mengharapkan seluruh peserta memiliki keterlibatan langsung dalam perencanaan dan pelaksanaan tugas-tugas mereka, seperti adanya rapat yang bertujuan untuk saling bertukar pikiran maupun menyumbangkan ide-ide yang dapat digunakan untuk menyelesaikan tugas dengan baik dan sempurna [9]. Tingkat pendekatan dalam ergonomi partisipasi adalah agar orang mampu untuk melakukan sendiri karena sudah mendapat latihan. Ergonomi partisipasi memerlukan kondisi tertentu untuk bisa 
berlangsung secara berhasil dan sukses yaitu adanya waktu yang cukup untuk ikut terlibat, manfaat yang diperoleh lebih besar dari pada biaya yang dikeluarkan, dan relevan dengan kebolehan orang yang dilatih untuk menangani masalah, serta cukup waktu berkomunikasi, cara berkomunikasi yang menguntungkan kedua belah pihak, tidak adanya perasaan dipaksa oleh pihak lain dan masih berada dalam wilayah kebebasan bekerja [9].

Ada komitmen terhadap rasa kepemilikan bersama, dimana setiap partisipan lebih menyukai pembagian bersama atau saling menguntungkan, yaitu hubungan yang mempertimbangkan kebutuhan dan manfaat. Jika hubungan antara partisipan didasarkan pada kebutuhan untuk saling membantu dan melengkapi, berarti relasi partisipasi akan berjalan normal dan baik, membiarkan nilai-nilai kemanusiaan dan kehidupan bisa dipahami tiap partisipannya, sesuai tahapannya masing-masing. Tetapi sebaliknya, jika suatu relasi partisipasi didasarkan untuk meraih manfaat dari orang lain, maka relasi tersebut akan berjalan tidak normal, karena disertai target dan kepentingan [10].

Masalah sampah tidaklah mungkin diselesaikan oleh pemda sendiri, tetapi butuh bantuan bank sampah sebagai wadah untuk mengubah paradigm kelola sampah di masyarakat. Jadi bank sampah bekerja di dua bidang, yaitu sosial dan ekonomi, sehingga menjadi tugas pemda-lah untuk mendampingi bank sampah. Selain bank sampah juga ada pengepul sampah swasta/mandiri. Para pengepul sampah ini menjadi kunci keberhasilan mendapatkan material/sampah yang bersih dari sumbernya untuk dibawa ke pabrik daur ulang. Saat ini beberapa pengepul sampah mandiri di Tangsel merasa khawatir dengan kemungkinan adanya Bank Sampah Induk (BSI), mereka mempertanyakan bagaimana peran BSI ini? Apakah akan menjadikan bank sampah dan pengepul sampah mandiri sebagai mitra ataukah akan mengambil alih peran dan pekerjaan mereka. Mereka mengkhawatirkan BSI ini hanya menjadi alat para oknum birokrasi untuk memonopoli bisnis sampah. Dikarenakan permasalahan diatas, maka ada tiga pengepul sampah mandiri yang bermaksud mendirikan paguyuban, agar suara mereka juga dapat terdengar. Penelitian ini adalah mengembangkan model sosial bisnis paguyuban pengepul sampah mandiri di kota Tangerang Selatan.

\section{METODE PENELITIAN}

Penelitian ini adalah eksploratory study, dimana dalam penelitian ini menggali (mengeksplorasi) sebanyak-banyaknya permasalahan yang dihadapi pengepul sampah mandiri. Unit yang dianalisis adalah pengepul sampah mandiri di kota Tangsel. Metode pengumpulan data dilakukan dengan wawancara terstruktur (in-depth interview), dilakukan dengan menggunakan peta empati. Peta empati digunakan untuk menganalisis demografi para pengepul sampah mandiri, dan mengembangkan pemahaman yang lebih baik tentang lingkungan, perilaku, kepedulian dan aspirasi. Dengan alat ini, akan dapat ditemukan model sosial bisnis sebagai pondasi pendirian paguyuban pengepul sampah mandiri. Alat Ukur yang dibangun berupa Peta Empati: memahami partisipan B2B (business to business): Bagian "lihat": Apa yang Anda lihat?

Jelaskan apa yang Anda lihat dalam lingkungan pengepul sampah di wilayah Anda.

- Seperti apa tampaknya?

- Siapa yang mengelilingi Anda?

- Siapa teman-teman Anda?

- Jenis penawaran apa yang Anda temukan setiap hari selain penawaran pasar?

- Apa masalah yang Anda temui?

Bagian "dengar": Apa yang Anda dengar?

Jelaskan bagaimana lingkungan mempengaruhi pengepul sampah.

- Apa yang dikatakan teman-teman pengepul Anda? 


\section{Helena Juliana Kristina, Wilson Kosasih, Lithrone Laricha Salomon}

- Apa yang dikatakan pasangan/keluarga Anda?

- Siapa yang benar-benar mempengaruhi anda? Dan bagaimana pengaruhnya terhadap pekerjaan Anda sebagai pengepul?

- Saluran/media/komunitas/instansi mana yang berpengaruh terhadap pekerjaan Anda sebagai pengepul?

Bagian "pikirkan" dan "rasakan".

Mencoba menguraikan apa yang ada dibenak Anda sebagai pengepul sampah.

- Apa yang benar-benar penting untuk Anda sebagai pengepul, tetapi Anda tidak mengatakannya secara terbuka?

- Bayangkan emosi Anda yang pernah timbul saat menegeluti profesi pengepul. Emosi apa saja yang timbul?

- Apakah ada hal dari pekerjaan yang membuat Anda khawatir dan menyebabkan Anda terbangun di malam hari?

- Coba Anda menggambarkan mimpi-mimpi dan aspirasi Anda sebagai seorang pengepul.

Bagian "katakan" dan "lakukan".

Membayangkan apa yang mungkin Anda katakan atau bagaimana perilaku Anda sebagai pengepul sampah di depan umum.

- Apa sikap Anda?

- Apa yang dapat Anda katakan kepada orang lain mengenai pekerjaan Anda?

- Berikan perhatian yang memadai untuk potensi konflik antara apa yang mungkin Anda katakan dan apa yang mungkin benar-benar Anda pikirkan atau katakan.

Bagian "rasa sakit".

Sakit hati apakah yang pernah Anda rasakan sebagai pengepul sampah?

- Apakah frustasi terbesar Anda sebagai pengepul sampah?

- Rintangan apa yang ada antara diri Anda dan yang ingin Anda capai?

- Risiko apa yang Anda takuti?

Bagian "perolehan".

Apa saja perolehan Anda sebagai seorang pengepul?

- Apa yang benar-benar ingin Anda capai?

- Bagaimana Anda mengukur kesuksesan sebagai pengepul?

- Pikirkan beberapa strategi yang dapat Anda gunakan untuk mencapai tujuan Anda.

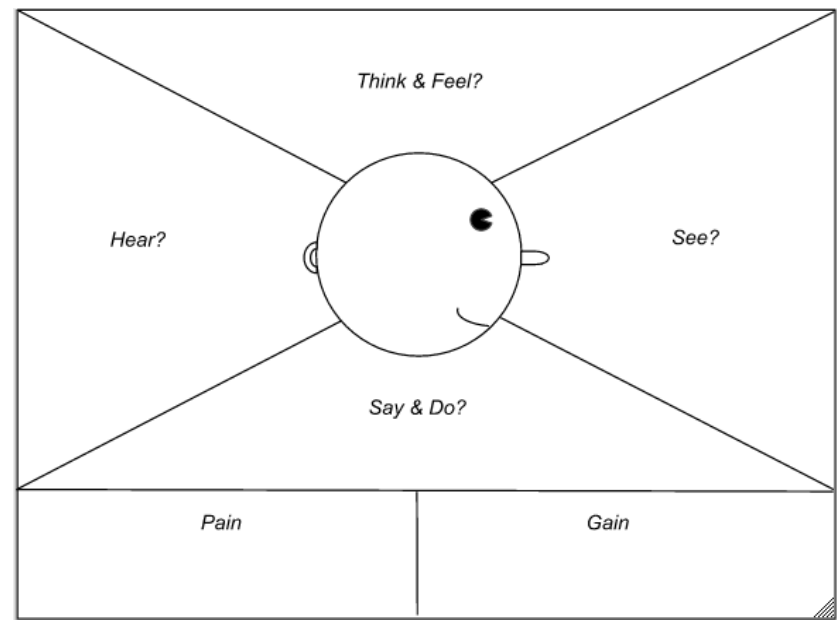

Gambar 1. Alat ukur Peta Empati B2B yang diberikan pada pengepul sampah 
Selanjutnya, hasil peta empati dirumuskan ke dalam kanvas model bisnis dengan blok bangunan yang diperlukan. Kanvas model bisnis adalah peta konseptual yang berfungsi sebagai bahasa visual dan gramatika yang sesuai. Dari model ini bisa didapatkan informasi mana saja yang akan diletakkan, serta memberikan panduan visual dan teks bagi semua informasi yang diperlukan untuk membuat sketsa sebuah model bisnis [11]. Setelah pemetaan dilakukan, hasilnya diutarakan dalam diskusi dengan pendekatan ergonomi partisipasi, guna mencapai pemahaman dan kesepakatan partisipan yang terlibat untuk mencapai suatu tujuan.

\section{HASIL DAN PEMBAHASAN}

Pemetaan demografi para pengepul sampah mandiri di kota Tangsel:

Bp Posma Sorimuda,

Memulai usaha pembuatan kompos tahun 2014, mulai menjadi pengepul sampah tahun 2016. Saat ini mengangkut sampah terpilah dari 29 Bank Sampah dan satu saung sampah di wilayah Tangsel. Hasil penimbangan dibawa ke pabrik dan pengepul besar. Karyawan yang dimiliki saat ini ada 2 orang. Tahun 2018 usaha sebagai pengepul sampah diberi nama SampahQu, dan telah memiliki aplikasi Apps SampahQu, yang dibuat oleh tim pengabdian masyarakat Program Studi Sistem Informasi danTeknik Industri, Universitas Pelita Harapan. SampahQu juga dipercaya oleh PT. Tetra Pak Indonesia untuk mengumpulkan kemasan tetra pak yang ada di wilayah Tangsel. Thn 2019, SampahQu kembali bekerja sama dengan institusi pendidikan: Teknik Industri UNTAR, PT.Tetra Pak Indonesia dan FORKOM Serpong Terrace, RT 03, RW 09, Serpong Tangsel, guna membantu pengangkutan sampah terpilah di Perumahan tersebut.

Bp Pujiono,

Mulai usaha dari tahun 2011 sampai sekarang. Pengambilan sampah tiap hari mencapai 1 ton. Dalam sebulan bisa mengumpulkan 10 ton sampah plastik yang kemudian dibawa ke pabrik untuk di daur ulang. Plastik di lapak sampah milik Bp Puji, dipilah-pilah, mulai jenis yang lemes, kasar, dan kantong plastik. Saat ini Bp Puji menggunakan dana sendiri untuk operasional lapaknya, pekerjaan sehari-hari dibantu 4 orang anak buah. Wilayah pengambilan sampah, mulai dari Pamulang, Kampung Utan, Ciputat hingga Pondok Cabe. Usia Bp Puji saat ini adalah 36 thn, mempunyai satu orang istri dan tiga orang anak.

Bp Abdul Khamid,

Mulai usaha tahun 2004 sebagai pengepul botol-beling di Tangsel. Pengumpulan saat ini sehari-hari sudah mencapai 3 ton, yang diambil dari 2 sampai 3 lapak sampah. Setelah dikumpulkan, botol-beling disortir berdasarkan warnanya, lalu dikirim ke pengepul besar di daerah Lebak, untuk di daur ulang di pabrik Tangerang dan Bekasi. Saat ini menggunakan dana sendiri untuk operasional dan sehari-hari dibantu 3 anak buah. Wilayah pengambilan meliputi Muncul, Pamulang, Depok, Ciputat dan Pondok Pinang. Usia Bp Dul saat ini adalah 43 thn, memiliki satu orang istri dan dua orang anak.

Hasil pemetaan Peta Empati B2B milik tiga pengepul sampah mandiri di kota Tangsel adalah sebagai berikut:

Peta Empati B2B milik Bp Dul (Gambar 2):

Saya mengakui bahwa teman-teman pengepul dan keluarga mendukung pekerjaannya. "Pekerjaan saya sebagai pengepul beling-kaca, juga ikut menjaga lingkungan agar bersih dari sampah". Menurut Bp Dul, yang paling berpengaruh terhadap pekerjaannya adalah semangat dari dalam diri saya sendiri, untuk tidak usah ragu dengan pekerjaannya. Biarpun sebagai pengepul sampah, Bp Dul juga ingin bisa membantu orang lain, "sesama teman 


\section{Helena Juliana Kristina, Wilson Kosasih, Lithrone Laricha}

pengepul baiknya saling membantu." Kesuksesan menurut Bp Dul, kalau ia sebagai pengepul mendapatkan ketenangan dalam bekerja. Bp Dul juga mempunyai mimpi agar suatu saat ia dapat mengurangi sampah. "Yang membuat saya khawatir adalah sampah yang semakin banyak, bagaimana dengan pekerjaan di lapak saya ini? Karena saya hanya punya 2 orang pekerja, itupun pekerja tidak tetap. Sangatlah sulit mencari orang yang mau bekerja di lapak sampah beling kaca." Bp Dul bekerja di lapak beling kaca hanya menggunakan sandal jepit, dan pakaian seadanya, menurut Bp Dul, dia sudah terbiasa kena pecahan kaca, sudah kebal. Emosi yang sering timbul dengan pekerjaan ini adalah saat kirim barang ke bos tetapi tidak ada tanggapan. Bp Dul merasa kurang diperhatikan dan diapresiasi pekerjaannya. "Sakit hati saya, ketika diomongi orang bahwa pekerjaan saya tidak pantas, frustasi terbesar saya, ketika orang tidak peduli akan kerja saya."

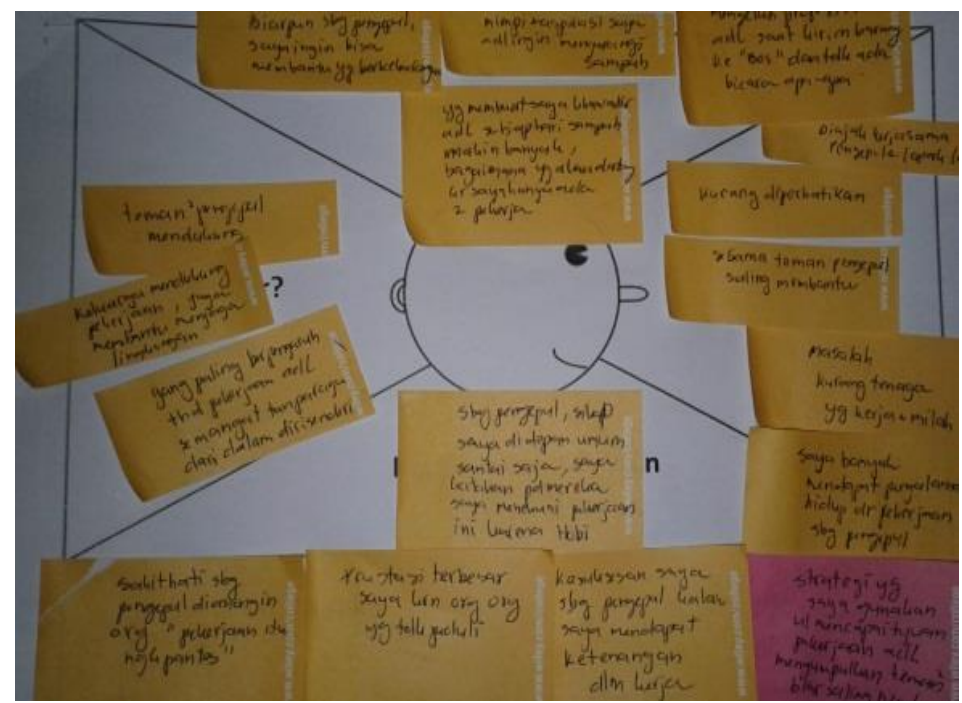

Gambar 2. Contoh Peta B2B Pengepul Bp Dul

Peta Empati B2B milik Bp Puji:

Sampah Plastik yang terkumpul di lapak sampah milik Bp Puji masih dalam keadaan kresek kotor atau masih bercampur jenis plastiknya. Sampah plastik tersebut kemudian dipilah-pilah dan disortir di lapak sebelum dibawa ke pabrik untuk di daur ulang. Pemilahan plastik mulai jenis kresek/asoy, jenis PE kotor, PE Sablon kotor, PP kotor, PP warna kotor. Setelah dipilah perjenisnya, sampah plastik tersebut di press manual, karena Bp Puji belum mempunyai mesin yang dapat mempermudah pekerjaannya. Bapak Puji juga prihatin, karena masih banyak orang buang sampah plastik di jalan dan mencemari lingkungan. Bapak Puji juga menyadari, dalam pekerjaannya, ia perlu berteman dengan pengepul barang bekas, RT, Ormas dan masyarakat sekitar. Bapak Puji berharap kehidupan keluarganya bisa mapan, dari yang kurang menjadi cukup. Pekerjaan sebagai pengepul adalah sangat penting untuk Bapak Puji, karena sebagai mata pencaharian untuk keluarga. Menurut Bapak Puji, komunitas pengepul di sekelilingnya yang paling berpengaruh terhadap pekerjaan Bapak Puji. Keluarga yang sangat mendukung dengan profesi pengepul yang saya pilih, karena selain menjaga lingkungan dari sampah, pekerjaan pengepul dapat dijadikan mata pencaharian, walaupun hasilnya tidak seberapa. Pernah ada temans mengatakan mengapa harus bekerja di dunia sampah, padahal banyak pekerjaan lain? "Saya katakan pada orang-orang bahwa pekerjaan saya, sangat menjanjikan sebagai pengepul, yang penting sikap saya di depan umum adalah menjaga nama baik saya di masyarakat. Kadang emosi Bapak Puji timbul, karena terlalu capek bekerja. Banyak tenaga yang terkuras, karena tidak adanya mesin yang mempercepat dan mempermudah pekerjaan Pak Puji dan anak buahnya. Dalam pekerjaannya, Bapak Puji 
juga menemui beberapa masalah, mulai dari tidak ada alat cacah plastik atau pengepres untuk memenuhi target pabrik, masalah dana operasional, masalah mencari pekerja. Saat ini Bp Puji menggunakan dana sendiri untuk operasional lapaknya. Pekerjaan sehari-hari dibantu 4 orang anak buah. Kesulitan lain yang dihadapi Bp Puji adalah susahnya mempertahankan dan mencari anak buah/orang yang mau membantu pekerjaan di lapak sampah plastik Bp Puji. Bp Puji sangat berharap, kelak dia bisa memiliki sebuah mesin press di lapaknya. Bp Puji menyadari dengan kemajuan teknologi, seharusnya pekerjaannya bisa jauh lebih dipermudah. Bapak Puji juga pernah diajak kerja sama dengan pabrik di Tangerang yang butuh pasokan bahan baku sampah plastik. Duka yang dialami Bapak Puji, saat bekerja sebagai pengepul sampah plastik adalah, saat ia ditinggal oleh orang/pekerja yang membantunya, frustasi ketika sampah plastik yang kumpulkan tidak ada nilai harganya. Bapak Puji berharap, bisa mendapatkan bantuan modal, bantuan pekerja, dan bantuan mesin yang bisa mempermudah pekerjaannya di lapak sampah plastik. Untuk hal tersebut Bapak Puji berusaha memperkuat pertemanan dengan pengepul lain.

Peta Empati B2B milik Bp Posma:

Menjadi pengepul punya prospek usaha yang baik, terlebih bila bisa langsung menjual ke pabrik. Keluargalah yang paling mendukung Bp Posma, agar tetap giat mengembangkan usaha. Bp Posma mengakui bahwa pekerjaannya adalah usaha daur ulang. Sebagai pengepul, Bp Posma mendapat keuntungan usaha dan pengetahuan jenis-jenis barang. "Saya katakan pada masyarakat bahwa usaha saya membantu mengurangi sampah yang terbuang, dan mengubahnya menjadi barang yang punya nilai jual." "Saya katakan pada masyarakat, bahwa dari usaha saya ini, saya ikut mengurangi sampah di kota Tangsel." Frustasi terbesar yang dialami Bapak Posma, ketika sampah yang dikumpulkannya ditolak oleh pabrik saat pengiriman. Contohnya, minyak jelantah yang dikumpulkannya dari bank sampah dan warga, ditolak oleh pabrik di Cikarang karena minyak jelantah tercampur air cukup banyak. Untuk hal ini Bp Posma mengalami kerugian, tetapi Bp Posma bertanggung jawab, beliau mencari perusahaan di Tangerang yang mau menampung minyak jelantah yang sudah tercampur air tersebut. Bapak Posma menyadari tidak boleh sembarangan membuang minyak jelantah yang sudah tercampur air ke lingkungan. Untuk mencegah terulang kembali hal diatas, Bapak Posma terus mengedukasi penggurus bank sampah dan warga, akan pentingnya kejujuran saat menimbang sampah terpilah. Selain itu, risiko yang Bp Posma takuti adalah harga sampah turun, karena masuknya sampah impor. Kedepannya yang ingin Bp Posma capai adalah bisa punya alat pengolahan sampah sendiri yang mempermudah pekerjaannya. Pekerjaan saya didukung oleh warga sekitar, juga didukung temans pengepul sekitar Pamulang dan Pondok Bekasi. Menurut saya, kondisi saat ini, semua pengepul masih berjalan sendiri-sendiri, belum punya wadah untuk kerja sama khususnya untuk pengiriman atau pertukaran barang antar pengepul. Contohnya seperti: "Saya pernah mendapat tawaran mengirim sampah styrofoam tapi harus ke Surabaya, padahal setahu saya pabriknya ada di Kerawang." Belum lagi masalah kemasan mika, styrofoam, dan plastik yang mengandung aluminium foil, untuk saat ini, tidak ada pabrik yang mau menerima. Emosi juga bisa timbul, ketika Bp Posma menyampaikan pendapat/ pemikiran ke Dinas terkait mengenai permasalahan sampah, tetapi tidak ditanggapi. Bp Posma mengakui bahwa institusi kampus dan perusahaan swasta turut berpengaruh baik terhadap pekerjaannya sebagai pengepul sampah. Pada tahun 2018, usaha Bp Posma sebagai pengepul sampah diberi nama "SampahQu". Usaha Bp Posma ini telah memiliki aplikasi Apps SampahQu, yang dibuat oleh tim pengabdian masyarakat Program Studi Sistem Informasi danTeknik Industri, Universitas Pelita Harapan. SampahQu juga dipercaya oleh PT. Tetra Pak Indonesia untuk mengumpulkan kemasan tetra pak yang ada 


\section{Helena Juliana Kristina, Wilson Kosasih, Lithrone Laricha}

di wilayah Tangsel. Pada tahun 2019, SampahQu kembali bekerja sama dengan institusi pendidikan: Teknik Industri UNTAR, Teknik Industri UPH, PT.Tetra Pak Indonesia dan FORKOM Serpong Terrace, RT 03, RW 09, Serpong Tangsel, guna membantu pengangkutan sampah terpilah di Perumahan tersebut.

Setelah pemetaan peta empati B2B dilakukan, hasilnya diberitahukan kepada para partisipan dalam diskusi (Gambar 3). Diskusi dihadiri 3 pengepul sampah dan perwakilan dari DPRD Tangsel. Dalam pembicaraan tersebut, disepakati bersama bahwa para partisipan bersedia mencoba mendirikan paguyuban pengepul sampah dengan pendekatan ergonomi partisipasi serta dibuatlah susunan kepengurusan paguyuban sebagai berikut:

Konsultan Paguyuban:

1. Bp Alex Prabu (DPRD Tangsel)

2. Helena Juliana Kristina (Teknik Industri - UNTAR Jakarta)

Ketua Paguyuban : Bp Posma Sorimuda

Koordinator Plastik : Bp Pujiono

Koordinator Beling : Bp Abdul Khamid

Koordinator Tetra Pak : Bp Posma Sorimuda

Sekretaris

: Salsabila Asyifa, S.E. (SampahQu)

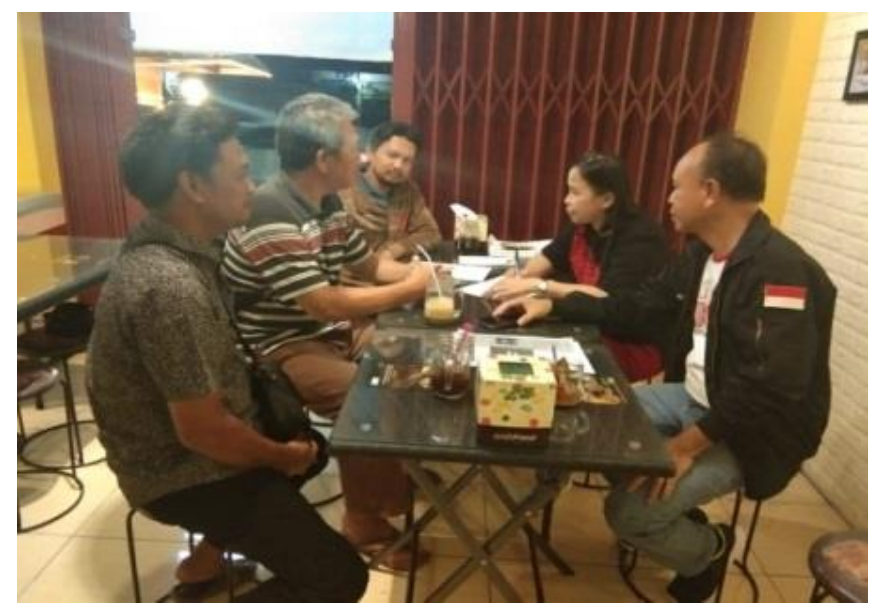

Gambar 3. Foto saat diskusi dengan pengepul sampah mandiri dan perwakilan dari DPRD Tangsel, 13 September 2019

Enam blok bangunan model sosial bisnis paguyuban pengepul Mandiri Tangsel telah dibentuk, dimana blok ini terdiri dari:

1. Segmen mitra: blok ini berisi partisipan yang melayani satu sama lain

2. Aktivitas utama: blok ini menggambarkan hal-hal terpenting yang harus dilakukan partisipan mitra agar model sosial bisnis dapat bekerja

3. Sumber daya utama: blok ini menggambarkan asset-aset terpenting yang diperlukan agar model sosial bisnis ini dapat berfungsi

4. Proposisi nilai: blok ini menggambarkan gabungan produk dan layanan yang menciptakan nilai untuk segmen mitra spesifik

5. Hubungan dengan mitra: blok ini menggambarkan berbagai jenis hubungan yang dibangun bersama mitra spesifik

6. Saluran: blok ini menggambarkan bagaimana segmen mitra berkomunikasi dalam memberikan proposisi nilai.

Olah hasil diskusi dan pemetaan menjadi draf model bisnis paguyuban pengepul mandiri kota Tangsel dapat dilihat pada Tabel 1. 
Tabel 1. Draf Model Sosial Bisnis Paguyuban Pengepul Sampah Mandiri Kota Tangsel

\begin{tabular}{|c|c|c|c|}
\hline Mitra Utama & Aktivitas Utama: & Proposisi Nilai: & Hubungan dengan Mitra: \\
\hline $\begin{array}{l}\text { a. Pengepul sampah di Tangsel: } \\
\text { pengumpul sampah terpilah } \\
\text { untuk disalurkan ke pabrik/ } \\
\text { pengepul besar. } \\
\text { b. Perusahaan/industri yang } \\
\text { menggunakan kemasan/ } \\
\text { asosiasi terkait: membantu } \\
\text { mewujudkan sustainable } \\
\text { business bagi anggota } \\
\text { paguyuban pengepul sampah, } \\
\text { sebagai bagian dari praktek } \\
\text { corporate social initiative. } \\
\text { c. Pabrik daur ulang/Pengepul } \\
\text { besar: mendaur ulang/membeli } \\
\text { sampah dari pengepul untuk } \\
\text { di daur ulang di pabrik. } \\
\text { d. DLH Tangsel: mitra setara } \\
\text { dengan paguyuban pengepul } \\
\text { sampah, saling memberi } \\
\text { manfaat untuk pelaksanaan } \\
\text { PERDA, guna mengurangi } \\
\text { sampah di kota Tangsel dan } \\
\text { mewujudkan sistem mana- } \\
\text { jemen sampah yang baik di } \\
\text { Tangsel. } \\
\text { e. DPRD Tangsel: pendamping } \\
\text { paguyuban pengepul sampah. }\end{array}$ & $\begin{array}{l}\text { a. Menambah sinergi positip } \\
\text { para mitra, yang tercermin dari } \\
\text { hasil kesatuan dan kerukunan } \\
\text { kerja sama para mitra. } \\
\text { b. Mengajak pengepul sampah } \\
\text { yang ada di kota Tangsel untuk } \\
\text { bergabung dalam paguyuban. } \\
\text { c. Mengembangkan kerja sama } \\
\text { antar pengepul sampah dan } \\
\text { DLH Tangsel untuk pelak- } \\
\text { sanaan PERDA. } \\
\text { d. Mengembangkan kerja sama } \\
\text { dengan mitra, guna mencari } \\
\text { solusi untuk permasalahan } \\
\text { sampah kemasan yang belum } \\
\text { bisa disalurkan ke pabrik. } \\
\text { e. Mengembangkan jejaring } \\
\text { kerja sama dengan para mitra } \\
\text { guna menumbuhkan kesadaran } \\
\text { di masyarakat Tangsel untuk } \\
\text { ikut melakukan pemilahan } \\
\text { sampah sejak dari sumbernya, } \\
\text { supaya kemasan lebih bersih } \\
\text { dari kontaminasi, dan } \\
\text { terciptanya jalur daur ulang } \\
\text { sesuai masing-masing tipe } \\
\text { kemasan yang dapat memberi- } \\
\text { kan sustainable business } \\
\text { untuk perusahaan/ industri. }\end{array}$ & 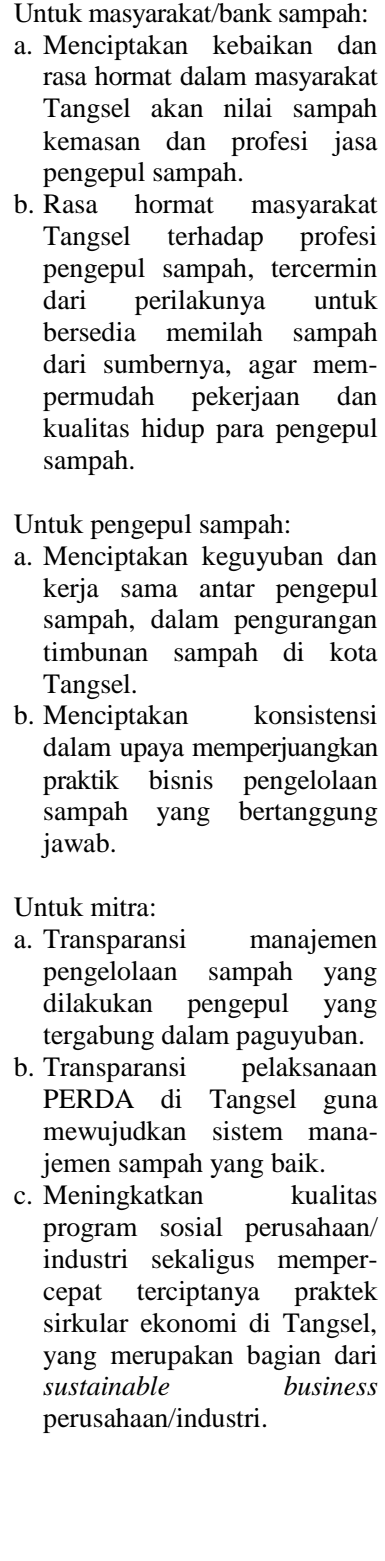 & $\begin{array}{l}\text { a. Paguyuban pengepul sampah } \\
\text { akan membuat proposal } \\
\text { kegiatan kepada mitra. } \\
\text { b. Mitra dapat menawarkan } \\
\text { proposal kegiatan kepada } \\
\text { paguyuban pengepul sampah. } \\
\text { c. Pertanggung jawaban pelak- } \\
\text { sanaan kegiatan proposal } \\
\text { disesuaikan dengan kesepa- } \\
\text { katan antara mitra yang } \\
\text { terlibat. } \\
\text { d. Setiap proposal/kegiatan harus } \\
\text { diketahui dan disetujui oleh } \\
\text { anggota paguyuban pengepul } \\
\text { sampah dan penggurusnya. }\end{array}$ \\
\hline
\end{tabular}

Note: Struktur biaya \& struktur pendapatan (untuk sementara ditiadakan, sampai Paguyuban Pengepul Sampah berbadan hukum)

Setelah draf Model Sosial Bisnis Paguyuban Pengepul Sampah terbentuk, disosialisasikan kepada beberapa partisipan lainnya, untuk dimintakan pendapat mereka. Hasil wawancara/ dengar pendapat narasumber lainnya, setelah draf model dibuat:

Bp. Sutiono Gunadi (pemerhati lingkungan hidup, warga Tangsel):

1. Penyebutan DLH sebagai mitra setara bagi paguyuban tampaknya perlu dikaji ulang. Lazimnya institusi pemegang regulasi relatif "di atas" karena bila setara mereka tidak bisa menerapkan regulasi yang ditetapkan KLHK bila tidak disetujui mitra setaranya. Status DLH idealnya mengayomi semua pengepul tanpa ada kepentingan pribadi pada oknum DLH.

2. Issue dibentuknya Bank Sampah Induk, patut dipelajari dari kota-kota yang sudah menerapkan Bank Sampah Induk, baik regulasi maupun operasionalnya. Semoga tidak sampai "mematikan" pengepul besar yang saat ini sudah mendukung Bank Sampah di level kelurahan. 


\section{Helena Juliana Kristina, Wilson Kosasih, Lithrone Laricha}

Perlu dipikirkan bila paguyuban gagal menyatukan seluruh pengepul tetapi muncul beberapa paguyuban serupa, guna menghindari persaingan yang tidak sehat.

Keinginan DPRD agar Tangsel memiliki pabrik pengolah sampah sendiri patut didukung asalkan pemkot Tangsel mampu menyediakan lahan karena pasti memerlukan lahan yang cukup luas untuk gudang penampungan dan pemasaran hasil daur ulang sampah.

3. Sebagai organisasi nirlaba paguyuban harus diatur agar anggotanya setara, misal bila pengepul harus memiliki izin penyimpanan maka semua harus memiliki. Perlu dikaji apakah penyimpanan sampah bukan B3 perlu izin.

Bp Henky Wibawa (Ketua Federasi Pengemasan Indonesia): Menurut saya sebaiknya dibentuk paguyuban dalam bentuk koperasi, agar mempunyai bargaining power, juga dapat saling melengkapi, karena bagaimanapun juga harus dilihat ini sebagai business as usual, yang tentunya memperhatikan skala ekonominya.

Alex Prabu (DPRD Tangsel -PSI): Saya setuju, ini bukan hanya kegiatan sosial tetapi suatu wadah untuk menampung pemulung dan pengelolaan sampah yang mampu mengurangi pembuangan ke kota dan sekaligus lapangan kerja baru bagi warga sekitar TPA.

Drs. Luhur Prajarto (Deputi Kelembagaan Kemenkop): Kalau para pengumpul sampah diwadahi dalam wadah yang legal, diharapkan akan memberikan nilai positif kepada anggotanya. Sampah-sampah yang dikumpul dan sudah dipilah-pilah, akan diproses oleh koperasi. Demikian juga untuk pemasaran hasil olahan sampah. Jadi nilai tambah tersebut, nantinya akan dirasakan manfaatnya oleh anggota koperasi. Untuk memfasilitasi dan memberikan pemahaman kepada pengumpul sampah dapat diberikan penyuluhan. Koperasi yang akan dibentuk berlokasi di Tangsel, maka perlu berkoordinasi dengan Dinaskop dan UKM kota Tangsel. Bisa menemui Ibu Dahlia, sekretaris, untuk meminta agar diberikan penyuluhan.

\section{KESIMPULAN}

Model Sosial Bisnis Paguyuban Pengepul Sampah Mandiri Kota Tangsel telah dikembangkan. Model ini dapat dikaji ulang oleh para partisipannya dengan mempertimbangkan masukkan dari para narasumber. Paguyuban yang terbentuk diharapkan dapat menjadi modal sosial yang menjembatani (bridging social capital), dimana hubungan-hubungan antara individu dan kelompok yang memilih untuk tidak secara bersama-sama, namun kenyataannya berada di sekitar kepedulian yang sama. Mendesain model dan menghidupinya tidak terlepas dari upaya para partisipannya. Hal tersebut sebagai bentuk usaha yang bertujuan untuk mewujudkan komunitas pengepul sampah mandiri yang bersifat saling memahami, saling menguntungkan dalam sisi ekonomi, bisnis yang stabil sehingga tercipta kesejahteraan bersama dalam pengelolaan sampah dalam penerapan sirkular ekonomi.

\section{UCAPAN TERIMA KASIH}

Penelitian ini dapat terlaksana dengan baik atas dukungan PT. Tetra Pak Indonesia dan Lembaga Penelitian dan Pengabdian Masyarakat, Universitas Tarumanagara. Pada Kesempatan ini Penulis mengucapkan terima kasih kepada semua pihak yang mendukung, dan memberikan wawasan yang sangat membantu penelitian ini. 


\section{DAFTAR PUSTAKA}

[1] Republik Indonesia. 2008. Undang-undang Republik Indonesia No. 18 Tahun 2008 Tentang Pengelolaan Sampah. Lembaran Negara RI Tahun 2008, No. 69. Jakarta, ID: Sekretariat Negara.

[2] H. Asroel. 2019. Bank Sampah: Masalah dan Solusi. Watampone, ID: Penerbit CV. Syahadah Creative Media.

[3] A. Sumargi. 2018. Keynote Speech Kepala Seksi Pemantauan Direktorat Pegelolaan Sampah pada Kementerian Lingkungan Hidup dan Kehutanan Republik Indonesia. Voice recording at Seminar "Winning the Future, Today ". Sheraton Hotel Gandaria City Jakarta, ID: GAPMMI dan Tetra Pak Indonesia.

[4] H. J. Kristina. 2014. Program Pemberdayaan Bank Sampah Masyarakat Berkelanjutan sebagai Salah Satu Penggerak Terwujudnya Reverse Logistic Manajemen Rantai Pasok Manufaktur Berkelanjutan. Paper presented at Seminar Nasional Teknologi dan Sains 2014. Jakarta, ID: Fakultas Teknik Universitas Tarumanagara.

[5] H. J. Kristina, E. Jobiliong dan A. Christiani. 2019. Model Rantai Pasok Daur Ulang Kemasan Karton yang Mengandung Aluminium Foil. Laporan Penelitian Prodi Teknik Industri Universitas Pelita Harapan, No: P-041-M/FaST/VIII/2018.

[6] H. J. Kristina, W. Kosasih dan L. L. Salomon. 2019. Ergonomi Partisipasi dalam Mempromosikan Pengelolaan Sampah Mandiri dan Daur Ulang Kemasan Tetra Pak. Jurnal Bakti Masyarakat Indonesia, 2(2), pp. 38-48. DOI: https://doi.org/10.24912/jbmi.v2i2.7223

[7] H. J. Kristina, W. Kosasih dan L. L. Salomon. 2020. Evaluasi Penanganan Kemasan UBC di Bank Sampah dan Pengepulnya Menggunakan Pendekatan Ergonomi Partisipasi. Jurnal Ilmiah Teknik Industri, 8(2), pp. 122-131. DOI: https://doi.org/10.24912/jitiuntar.v8i2.6692

[8] M. Adnyana. 1999. Penerapan Pendekatan Ergonomi Partisipasi dalam Meningkatkan Kinerja Industri. Paper presented at Seminar Nasional Ergonomi Reevaluasi Penerapan Ergonomi dalam Meningkatkan Kinerja Industri. Surabaya, Indonesia.

[9] P. Vink, A. S. Imada dan K. J. Zink. 2008. Defining Stakeholder Involvement in Participatory Design Processes. Journal of Applied Ergonomics, 39, pp 519-526.

[10] S. Clayton dan G. Myers. 2015. Conservation Psychology: Understanding and Promoting Human Care for Nature. UK: John Wiley \& Sons Ltd.

[11] A. Osterwalder dan Y. Pigneur. 2012. Business Model Generation. Jakarta, ID: PT. Elex Media Komputindo. 